\title{
Stubble Height, Basal Cover, and Herbage Production Relationships in Grasslands of Northern Greece
}

\author{
VASILIOS P. PAPANASTASIS
}

\begin{abstract}
Leaving an amount of mulch at the end of the grazing period, before the new growing season starts is vital in maintaining productivity in grasslands on a sustained yield basis. Mulch was expressed as stubble height at 6 levels $(0,3,6,9,12$, and $15 \mathrm{~cm})$ and was related to basal cover and herbage production attained at the end of the growing season for 5 consecutive years. The research was conducted on 3 perennial grassland sites with a Mediterraneantype climate, representing the low, middle, and high (subalpine) ecological zones in northern Greece. Bare soil was significantly increased with nearly all stubble heights as compared to the control while mulch cover had an opposite response. There were significant changes in the absolute cover of the dominant species, especially perennial bunchgrasses, but the overall grass and forb cover was not significantly affected. Stubble heights of $12 \mathrm{or} 15 \mathrm{~cm}$ at the low site and 6 to $15 \mathrm{~cm}$ at the other two sites produced the highest yields. These were not significantly different from the control, indicating that the middle and the high sites can withstand closer grazing than the low site.
\end{abstract}

One of the main criteria for determining proper use of grasslands is the amount of plant residue left on the ground at the end of the grazing period and before the new growing season starts (Heady 1975, Biswell and Liacos 1977). This material, also called mulch, is vital in maintaining productivity by improving soil structure and fertility, increasing infiltration rate and promoting an ideal botanical composition (Dyksterhuis and Schmutz 1947, Heady 1956, Tomanek 1969). However, although the amount of mulch correlates directly with production, an excess may reduce herbage growth, depending on the particular environment involved (Bartolome et al. 1980).

Leaving a certain quantity of mulch on a perennial grassland at the end of the grazing period would mean that all plants are grazed to a certain average stubble height. Therefore, obtaining the optimum stubble height at the end of the grazing period would secure as well the optimum amount of mulch.

In general, mulch has been expressed as weight in forage utilization studies (Dyksterhuis and Schmutz 1947, Heady 1956, Bement and Klipple 1956). This is not a very practical management tool. Instead, measuring stubble height is a much easier practice for users. This would be of considerable importance for Greece where grasslands are communally used (Papanastasis 1981a). For the proper use of these areas, it would be necessary to employ criteria easily measured and understood by both graziers and range technicians.

The purpose of this paper was to study the effect of stubble height, established at the beginning of the growing season, on species composition and herbage production attained at season's end and develop proper use standards for grasslands of northern Greece.

\section{Study Sites}

The research was conducted on 3 sites along an elevation gra-

Author is a range scientist, Forest Research Institute, Vassilika, Thessaloniki, Greece.

Manuscript accepted October 12, 1984 dient representing 3 major, ecologically different, grassland areas in Macedonia, northern Greece. One site was located on the lowelevation zone, $10 \mathrm{~km}$ from the sea coast at an altitude of $60 \mathrm{~m}$; the second site was inland, on the middle-elevation zone at $650 \mathrm{~m}$ altitude; the third site was located on the subalpine zone at an altitude of $1,500 \mathrm{~m}$. All grassland sites had been ungrazed or lightly grazed for the last 15 to 20 years and represented communities of a relatively steady state that could be considered as a climax.

Vegetation was diverse, with most of the species being annual at the low site and perennial at the other 2 sites. The dominant species, however, were perennial grasses: warm-season at the low, warm-and cool-season at the middle, and cool-season at the high site. There were also a few species of half-shrubs growing at the subalpine site. A detailed account of the species structure of the 3 sites was documented (Papanastasis 198Ib).

Climate was of the Mediterranean-type, semiarid at the low site, subhumid at the middle, and humid at the high site, with annual rainfall 430,630 , and $940 \mathrm{~mm}$ and mean air temperature $15.5,13.0$, and $8.4^{\circ} \mathrm{C}$ respectively for the 3 sites (Papanastasis 1982). Soils were of different origin but relatively deep and fertile at all sites.

\section{Methods}

At each site, 6 stubble heights $(0,3,6,9,12$, and $15 \mathrm{~cm})$ and a control were arranged in a randomized block design. Each treatment was applied on $9 \mathrm{~m}^{2}$ and replicated 3 times.

At the low and middle sites, the experiment was established at the end of the summer, just before the new growing season started (late August, 1975); at the high site, when vegetation became dry and before the advent of the winter period (early October, 1974). Cutting was done by hand scissors to the desired height and the material produced was removed. To secure a uniform height, elevated quadrats were used as "guides". These were $0.04 \mathrm{~m}^{2}$ each and were supported by 4 rods with height equal to the desired stubble height. In the "zero" treatment no guide was used and plants were cut to the ground level.

Treatments were repeated at all sites for $S$ consecutive years. However, to estimate the weight of mulch remaining with the various stubble heights, the same treatments were applied $I$ additional year, and 2 samples from each plot (except the ones with 0 stubble height) were collected right af ter their establishment. Sampling was done with a quadrat $\left(0.25 \mathrm{~m}^{2}\right)$ by cutting the plant material to ground level with scissors and weighing it after drying at $70^{\circ} \mathrm{C}$.

Measurements or cover, and herbage production were taken 1 growing season after the establishment of stubble height and at the time of peak aboveground live biomass. This was early-June for the low site, mid-June for the middle, and mid-August for the high site (Papanastasis 1982). Basal cover and species composition were measured with a 10-point frame (10 frames/plot). Herbage production was sampled the same way as mulch. In the laboratory, the current year's growth was separated by hand from the old growth and weighed after oven-drying at $70^{\circ} \mathrm{C}$.

The above measurements were repeated for 5 consecutive years, from 1976 to 1980 at the low and middle sites and from 1975 to 




Fig. 1. Relation between stubble height and basal cover at the three sites (cover values are means of the 5-year experimental period).

Table 1. Basal cover (\%) of the dominant species at the six stubble heights and the control at the three sites (values represent the 5-year means).

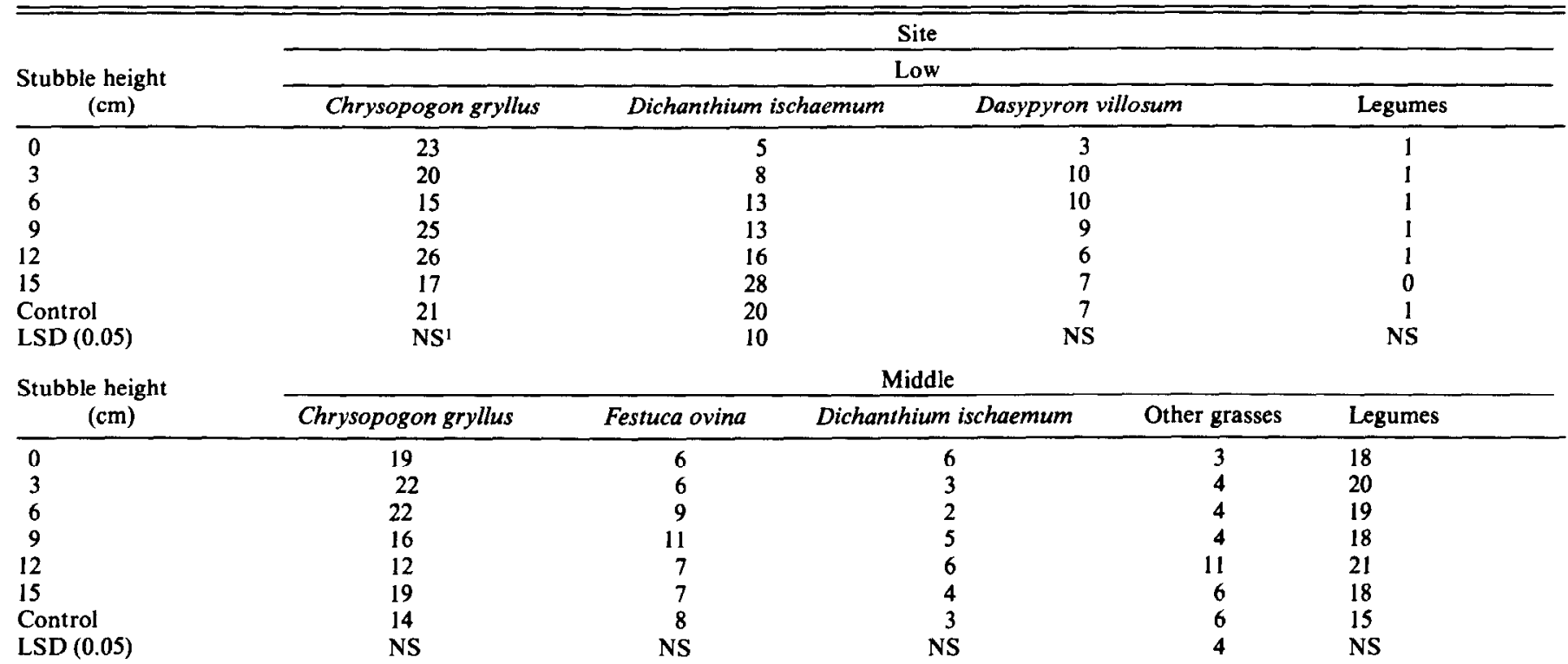

Stubble height

\begin{tabular}{lcccc} 
Stubble height & Calamagrostis varia & Festuca varia & Brachypodium pinnatum \\
\hline 0 & 8 & 2 & 3 & 4 \\
3 & 19 & 4 & 4 & 4 \\
6 & 17 & 6 & 6 & 14 \\
9 & 14 & 6 & 3 & 3 \\
12 & 16 & 7 & 5 & 5 \\
15 & 23 & 8 & 5 & 5 \\
Control & 16 & 4 & NS & 5
\end{tabular}


1979 at the high site. To avoid overlapping of herbage samples among years, the exact positions of the sampling quadrats were marked on the plots each year.

Absolute basal cover (percent of total observations) was used to characterize the relationship of bare soil, mulch, and vegetation. It was also used to describe components of vegetation rather than relative species composition since it provided a more reliable indication of actual increases or decreases. Absolute basal cover (basal cover) data were subjected to analysis of variance after averaging over the 5-year experimental period. Herbage data were analyzed both for each year and for the 5 years collectively at each site (Cochran and Cox 1957). When the $F$ test was significant, the effects of each treatment were compared with the control by the least significant difference (LSD) value at the 0.05 level.

\section{Results and Discussion}

\section{Basal Cover ${ }^{1}$}

Cutting to different stubble heights affected basal cover. More specifically, bare soil was increased as stubble height decreased. All treatments were significantly different from the control over the 3 sites, except at the high site where stubble heights 12 and $15 \mathrm{~cm}$ had as much bare soil as the control plots. On the contrary, the cover of mulch was significantly reduced with all stubble heights, except with the $15-\mathrm{cm}$ height of the low site, which had as much mulch cover as the control (Fig. 1). These findings indicated that the lower the stubble height at the beginning the more bare soil and the less mulch cover there will be at the end of the growing season.

Grass basal cover tended to decrease with the reduction of stubble height at all sites while forb cover showed an opposite trend (Fig. 1). These changes, however, where not found to be significant. Nevertheless, there were significant changes in some of the individual species or groups of species at all sites.

At the low site, woolly-beard grass (Dichanthium ischaemum), a dominant perennial bunchgrass, was significantly reduced in basal cover with stubble heights 0 and $3 \mathrm{~cm}$ as compared to the control. On the contrary, brushgrass (Chrysopogon gryllus), a codominant perennial bunchgrass, was not significantly affected by any of the 6 stubble heights tested. The difference in response of these 2 grasses seems to be due to their different growth form. The bunches of the former grass are erect and thick, while the bunches of the latter are prostrate and loose. Also, no significant differences were found in basal cover of the annual hairy goatgrass (Dasypyron villosum) as well as of legumes, including annual species of Trifolium, Medicago, Lathyrus and Hymenocarpus (Table 1).

At the middle site, wolly-beard grass did not show any significant response to the lower stubble heights as at the low site, apparently due to its small proportion in the vegetative cover (less than 10\%). Also, no significant changes in basal cover were obtained with the other 2 dominant grasses, brushgrass and sheep fescue (Festuca ovina) as well as with legumes, including hop clover (Trifolium campestre), hare's foot clover (T. arvense), purple clover (T. purpureum), tufted vetch (Vicia tenuifolia), and sickle medic (Medicago falcala). The basal cover of the subdominant perennial grasses, however, including orchardgrass (Dactylis glomerata), couchgrass (Agropyron repens), crested hairgrass (Koeleria cristata), and cat's tail grass (Phleum montanum) was significantly increased with stubble height $12 \mathrm{~cm}$ as compared to the control (Table 1).

At the high site, only the basal cover of the variable fescue (Festuca varia) was significantly reduced by the "zero" stubble height, while variable reedgrass (Calamagrostis varia) and torgrass (Brachypodium pinnatum) were not affected by any treatment. On the other hand, legumes including owl-headed clover (Trifolium alpestre) and meadow clover ( $T$. medium) were significantly increased in basal cover with stubble heights 6,9 , and $12 \mathrm{~cm}$ as compared to the control (Table 1).

In general, the changes in basal area caused by the treatments

INomenclature of plant species follows Flora Europaea, 1964-1983, Cambridge. were not dramatic indicating the high resilience of the 3 grassland ecosystems studied. However, low stubble heights $(0$ and $3 \mathrm{~cm})$ tended to reduce the dominant bunchgrasses while middle heights $(6$ to $12 \mathrm{~cm}$ ) favored the subdominant perennial grasses and legumes. These results basically agree with what was found by other researchers evaluating the effect of mulch in grasslands of the United States (Weaver and Rowland 1952, Heady 1956, Albertson and Tomanek 1965).

\section{Herbage Production}

The effect of stubble height on herbage production was variable. At the low site, herbage yields associated with the various stubble heights were significantly lower than the control during the first 3 years. In the remaining 2 years, the yields were restored at least in the higher stubble heights. After 5 years the 12 and $15-\mathrm{cm}$ treatments were not different from the control (Table 2). This indicated

Table 2. Mean herbage production $\left(\mathrm{g} / \mathrm{m}^{2}\right)$ associated with the different stubble heights and the control plots for each of three sites for 5 consecutive years.

\begin{tabular}{|c|c|c|c|c|c|c|}
\hline \multirow{3}{*}{$\begin{array}{c}\text { Stubble } \\
\text { height } \\
(\mathrm{cm})\end{array}$} & \multicolumn{6}{|c|}{ Site } \\
\hline & \multicolumn{6}{|c|}{ Low } \\
\hline & 1976 & 1977 & 1978 & 1979 & 1980 & $\begin{array}{c}5 \text {-year } \\
\text { mean }\end{array}$ \\
\hline 0 & 133 & 110 & 248 & 150 & 172 & 163 \\
\hline 3 & 111 & 106 & 211 & 230 & 227 & 177 \\
\hline 6 & 115 & 105 & 280 & 231 & 226 & 191 \\
\hline 9 & 143 & 95 & 233 & 255 & 228 & 191 \\
\hline 12 & 150 & 113 & 229 & 216 & 267 & 195 \\
\hline 15 & 142 & 106 & 334 & 236 & 262 & 216 \\
\hline Control & 240 & 145 & 271 & 280 & 304 & 248 \\
\hline \multirow{2}{*}{$\begin{array}{l}\text { LSD } \\
\quad(0.05)\end{array}$} & & & & & & \\
\hline & 77 & 22 & 71 & 65 & 66 & 28 \\
\hline Stubble & \multicolumn{6}{|c|}{ Middle } \\
\hline
\end{tabular}

Stubble
height

\begin{tabular}{ccccccc}
$\begin{array}{c}(\mathrm{cm}) \\
0\end{array}$ & 1976 & 1977 & 1978 & 1979 & 1980 & mean \\
\hline 3 & 235 & 226 & 310 & 235 & 290 & 259 \\
6 & 270 & 254 & 364 & 242 & 307 & 287 \\
9 & 268 & 250 & 418 & 346 & 339 & 324 \\
12 & 274 & 294 & 463 & 371 & 445 & 369 \\
15 & 206 & 260 & 352 & 413 & 453 & 337 \\
Control & 272 & 257 & 424 & 349 & 452 & 351 \\
LSD & 266 & 295 & 425 & 409 & 446 & 368 \\
$(0.05)$ & NS & NS & NS & 95 & 111 & 49 \\
& & & & High & & \\
Stubble & & & & & & 5 -year \\
height & & & & 1978 & 1979 & mean \\
$(\mathrm{cm})$ & 1975 & 1976 & 1977 & 127 & 221 & 203 \\
\hline 0 & 262 & 199 & 206 & 167 & 298 & 264 \\
3 & 318 & 327 & 211 & 349 & 356 \\
6 & 416 & 398 & 349 & 209 & 409 & 378 \\
9 & 503 & 400 & 332 & 313 & 342 & 393 \\
12 & 388 & 460 & 355 & 333 & 429 & 374 \\
15 & 417 & 445 & 378 & 298 & 330 & 391 \\
Control & 362 & 462 & 333 & 387 & 410 & 391 \\
LSD & & & & & & \\
$(0.05)$ & NS & 112 & 85 & 115 & 73 & 49 \\
\hline
\end{tabular}

INonsignificant at 0.05 .

that any cutting was initially a stress to the system and recovery in herbage production began in the fourth year. The recovery, however, was not complete except for the higher stubble heights.

At the middle site, the results were much different since no significant differences were produced among the various treatments for the first 3 years. In the remaining 2 years, stubble heights of 6 to $15 \mathrm{~cm}$ gave as much herbage as the control (Table 2). Similar results were found at the high site, except that the 6 to $15-\mathrm{cm}$ stubble heights produced as much yield as the control beginning the second year of the study (Table 2). A delay of 1 year in response 
Table 3. Mulch weight $\left(\mathrm{g} / \mathrm{m}^{2}\right)$ and percent of control (\%) corresponding to the stubble height treatments at the end of the experimental period.1

\begin{tabular}{|c|c|c|c|c|c|c|}
\hline \multirow{2}{*}{$\begin{array}{l}\text { Stubble } \\
\text { height } \\
\text { (cm) }\end{array}$} & \multicolumn{2}{|c|}{ Low site } & \multicolumn{2}{|c|}{ Middle site } & \multicolumn{2}{|c|}{ High site } \\
\hline & $\begin{array}{l}\text { Weight } \\
\left(\mathrm{g} / \mathrm{m}^{2}\right)\end{array}$ & $(\%)$ & $\begin{array}{l}\text { Weight } \\
\left(\mathrm{g} / \mathrm{m}^{2}\right)\end{array}$ & $(\%)$ & $\begin{array}{l}\text { Weight } \\
\left(\mathrm{g} / \mathrm{m}^{2}\right)\end{array}$ & $(\%)$ \\
\hline $\begin{array}{l}0 \\
3 \\
6\end{array}$ & $\begin{array}{r}0 \\
114 \\
172\end{array}$ & $\begin{array}{r}0 \\
17 \\
25\end{array}$ & $\begin{array}{r}0 \\
109 \\
226 \\
\end{array}$ & $\begin{array}{r}0 \\
18 \\
37\end{array}$ & $\begin{array}{r}0 \\
344 \\
630 \\
\end{array}$ & $\begin{array}{r}0 \\
29 \\
54\end{array}$ \\
\hline $\begin{array}{r}9 \\
12\end{array}$ & $\begin{array}{l}276 \\
2992 \\
\end{array}$ & $\begin{array}{l}40 \\
43\end{array}$ & $\begin{array}{l}242 \\
346\end{array}$ & $\begin{array}{l}40 \\
57\end{array}$ & $\begin{array}{l}655 \\
731\end{array}$ & $\begin{array}{l}56 \\
62\end{array}$ \\
\hline $\begin{array}{l}15 \\
\text { Control } \\
\text { LSD } \\
(0.05)\end{array}$ & $\begin{array}{l}516 \\
691 \\
110\end{array}$ & $\begin{array}{r}75 \\
100\end{array}$ & $\begin{array}{l}367 \\
606\end{array}$ & $\begin{array}{r}61 \\
100\end{array}$ & $\begin{array}{r}819 \\
1178\end{array}$ & $\begin{array}{r}70 \\
100\end{array}$ \\
\hline
\end{tabular}

'Mulch was measured in late August, 1980 at the low and middle sites and in early October, 1979 at the high site.

2 Underlined mulch means correspond to the lowest stubble height that gave herbage yield statistically similar to the control in the last year of the experimental period (see Table 2).

to mulch treatments was also found on perennial grasslands in California (Bartolome et al. 1980).

The differences among sites can be explained by the variation in species structure and the climatic conditions of the 3 grasslands studied. The low site is dominated by woolly-beard grass comprising almost $50 \%$ of the peak herbage yield; on the contrary, the middle and high sites have a more balanced structure (Papanastasis $198 \mathrm{lb}$ ). Since woolly-beard grass is favored by accumulation of mulch, relatively low stubble heights led to its reduction and consequently to the reduction of the total herbage yield. This was not the case with the other 2 sites, where the reduction of the dominant bunchgrasses was compensated by the increase of other grasses or forbs, provided that the stubble heights were not too low. Moreover, Papanastasis (1982) reported that there is a considerable variation in herbage production due to weather changes from one year to the next and that this variation is much greater at the low site than at the other 2 sites. This may explain the different herbage yields produced by the same stubble heights among years, especially at the low site.

The year effect on herbage production was verified by the combined analysis of variance for all 5 years, which showed significant results among years, among the 7 treatments ( 6 stubble heights and the control) and between years and treatments. When the herbage means over the 5 years were compared (Table 2) it was found that stubble heights of 0 or $3 \mathrm{~cm}$ produced generally lower yields, while stubble heights of 6 to $15 \mathrm{~cm}$ were not significantly different from the control at the middle and high sites. At the low site, however, all heights had significantly lower yields than the control.

Therefore, $6 \mathrm{~cm}$ can be considered as the lowest stubblc height to secure maximum herbage production for the middle and the high sites: at the low site, $12 \mathrm{~cm}$ may be considered the lowest possible stubble height, since it gave as much herbage production as the control for the last 2 years of the study. Herbage production was significantly reduced at all sites below these stubble heights, indicating that the grasslands started to deteriorate.

\section{Relation of Stubble Height with Weight}

Weights of mulch corresponding to the various stubble heights used in this study as determined at the end of the experimental period are reported (Table 3 ). Although the values are only indications of annual weights during the 5 years of the experiment, they do show that relatively high amounts of mulch are related to high herbage production at the low and high sites as compared to the middle site. This may be due to the different climatic conditions.

At the low site, representing a semiarid environment, the large amounts of mulch apparently improve soil moisture conditions by increasing infiltration rate, reducing runoff, and decreasing evapo- ration, while at the high site with a cold environment to ameliorate and stabilize the soil surface temperatures (Tomanek 1969). The smaller amounts of mulch required at the middle site perhaps reflect the intermediate climatic conditions prevailing at the midelevation ecological zone of northern Greece (Papanastasis 1982).

\section{Management Implications}

The results of this study can be applied in practice only with certain approximation because they refer to ungrazed grasslands and they presuppose uniform stubble height, which is impossible to get under actual grazing conditions. However, to the extent that grazing can be simulated by clipping, these results indicated that middle and high elevation grasslands can withstand closer grazing than the grasslands on the low elevation zone; moreover, all grasslands deteriorate with close grazing (below 3-cm stubble height). Therefore, stubble height can be used as a guide for applying proper use and thus halting range deterioration in the grasslands of northern Greece. Mulch at the beginning of the growing season should be at least $43 \%, 37 \%$, and $54 \%$, respectively, of the total above-ground biomass for the low, middle, and high elevation grasslands in order to secure maximum sustained yield at the end of the season. Apparently proper grazing leads to a reduction of certain perennial bunchgrasses which are generally less desirable to livestock, especially sheep, and favors more desirable species of grasses and forbs, including legumes, thus resulting in increased animal production. However, additional research with grazing animals would be needed to study this important aspect.

\section{Literature Cited}

Albertson, F.W., and G.W. Tomanek. 1965. Vegetation changes during a 30-year period on grassland communites near Hays, Kansas. Ecology 46:714-720.

Bartolome, J.W., M.C. Stroud, and H.F. Heady. 1980. Influence of natural mulch on forage production on differing California annual range sites. J. Range Manage. 33:4-8.

Bement, R.E., and G.E. Klipple. 1956. A pasture comparison method of estimating utilization of range herbage on the Central Great Plains. J. Range Manage. 12:296-298.

Biswell, H.H., and L.G. Liacos. 1977. Range Management. Thessaloniki, (In Greek).

Cochran, W.G., and G.M. Cox. 1957. Experimental designs. John Wiley \& Sons, Inc.

Dyksterhuis, E.J., and E.M. Schmutz. 1947. Natural mulches or "litter" of grasslands: with kinds and amounts on a southern prairie. Ecology. 28:163-179.

Heady, H.F. 1956. Changes in a California plant community induced by manipulation of natural mulch. Ecology. 37:798-812.

Heady, H.F. 1975. Rangeland Management. McGraw Hill Co.

Papanastasis, V.P. 1981a. The rangelands of Greece. Rangelands. 3:241-242.

Papanastasis, V.P. 1981b. Species structure and productivity in grasslands of northern Greece. p. 205-217. In: N.S. Margaris and H.A. Mooney (eds). Components of productivity of Mediterranean-climate regions. Basic and applied aspects. T: VS 4. Dr. Jung. Pub., the Hague.

Papanastasis, V.P. 1982. Production of natural grasslands in relation to air temperature and precipitation in northern Greece. Thessaloniki. (In Greek)

Tomanek, G.W. 1969. Dynamics of mulch layer in grassland ecosystems. p. 225-240. In: R.L. Dix and R.G. Beidreman (eds). The grassland ecosystem, a preliminary synthesis. Range Sci. Ser. No. 2. Colorado State University.

Weaver, J.E., and N.W. Rowland. 1952. Effects of excessive natural mulch on development, yield, and structure of native grassland. Bot. Gaz. 114:1-19. 